\title{
A Simple Electronic Technique for Real-Time Indoor Monitoring of Radon Concentration
}

\author{
Y.A. Abdel-Razek ${ }^{1}$, W. Abd El-Basit ${ }^{2 *}$, A.M. Abdel-Maksood ${ }^{1}$, F.A.S. Soliman ${ }^{1}$ \\ ${ }^{1}$ Nuclear Materials Authority, P. O. Box 530, Maadi-11728, Cairo, Egypt \\ ${ }^{2}$ Res. Lab., Physics Dept., Faculty of Women for Arts, Science, and Education, Ain-Shams Univ., \\ Cairo, Egypt
}

\begin{abstract}
Indoor radon concentrations were determined with the use of simple electronic systems were commonly used as detectors for different environmental pollutions. In this concern, a potentially very simple life-saving detector-a radon detector was investigated. Where, it is well known that radon gas is one of the most dangerous gases, as well, it leaks easily for the ground. Radon concentrations have been measured, successfully, in different locations at the Nuclear Materials Authority site at Qattamya, Cairo, applying a prototype, simple ion-chamber monitor, and well established radon monitor (RTM 1688-2-Radon Monitor). The radon concentrations were found to be in the range of around $16.7-20.7 \mathrm{~Bq} . / \mathrm{m} 3$, although it shown to be with less levels (around $10.3 \mathrm{~Bq} . / \mathrm{m} 3$ ) at ventilated basement hall. The obtained data from both systems were found to be in an excellent agreement.
\end{abstract}

Keywords: Radon-gas, ionization chamber, Darlington pair transistor, Becquerel, radiation detection, temperature, relative humidity, and pressure.

\section{INTRODUCTION}

Radon (Rn) is a natural gas characterized with an odorless, colorless and tasteless gas and has a halflife time of 3.8 days $[1,2]$. Finally, it is considered to be a serious indoor pollutant and health hazard due to its radioactivity. This has tended to limit public concern, in sharp contrast to the anxiety generated over small risks in other areas involving ionizing radiation. Generally, radon isn't a new pollutant, where, normally, it exists in both indoor -and outdoor -environments. It was discovered as a radionuclide on 1990, and was suspected of being a cause of ill-health in 1924. Only in 1951 were radon daughters (as opposed to radon gas) suspected of being a cause of lung cancer in miners (Fig. 1a) [3]. Noting that, most radon gas breathed in is immediately exhaled and presents little radiological hazard. However, the decay products of radon (radon daughters) behave more like solid materials than a gas and are themselves radioactive. These solid decay products attach to atmospheric dust and water droplets which can then be breathed in and become lodged in the lungs and airways. Some decay products emit particularly hazardous radiation called alpha particles which cause significant damage to the sensitive cells in the lung. Finally, exposure to radon gas results -in the scarring of the lungs that often result-in disorders such as pulmonary fibrosis and silicosis (Fig. 1b). When the lungs get damaged, the lung tissue hardness, resulting in the inability of the lungs to expand properly. Radon has been recognized as a radiation hazard causing excess lung cancer among underground miners [4].

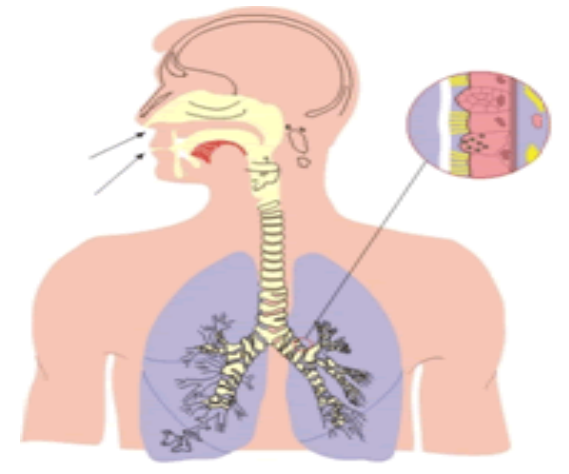

(a)

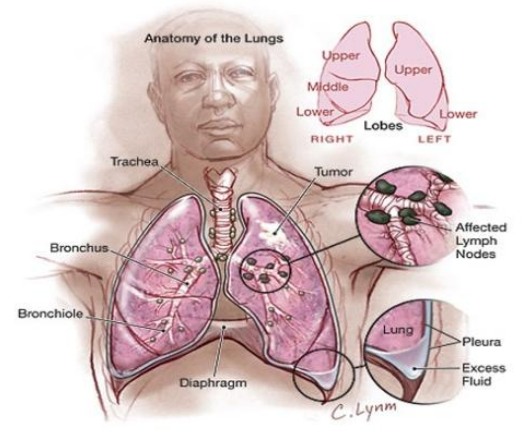

(b)

Fig1. Radon Effects on Lungs. 
Nevertheless it is an interesting element: despite being a 'noble gas' it will form compounds and if cooled to a solid. At the temperature of liquid air $\left(-195^{\circ} \mathrm{C}\right)$ it glows with an orange-red light (Fig. 2). Radon concentration in the atmosphere is usually measured in Becquerel per cubic meter $\left(\mathrm{Bq} / \mathrm{m}^{3}\right)$, the SI derived unit. Another unit of measurement common in the USA is picocuries per liter $(\mathrm{pCi} / \mathrm{L}) ; 1.0$ $\mathrm{pCi} / \mathrm{L}=37 \mathrm{~Bq} / \mathrm{m}^{3}$. Finally, universally, radon exposure levels, measured at indoor and outdoor were around $48 \mathrm{~Bq} / \mathrm{m}^{3}$ and $15 \mathrm{~Bq} / \mathrm{m}^{3}$, respectively (Fig. 3) [5, 6].

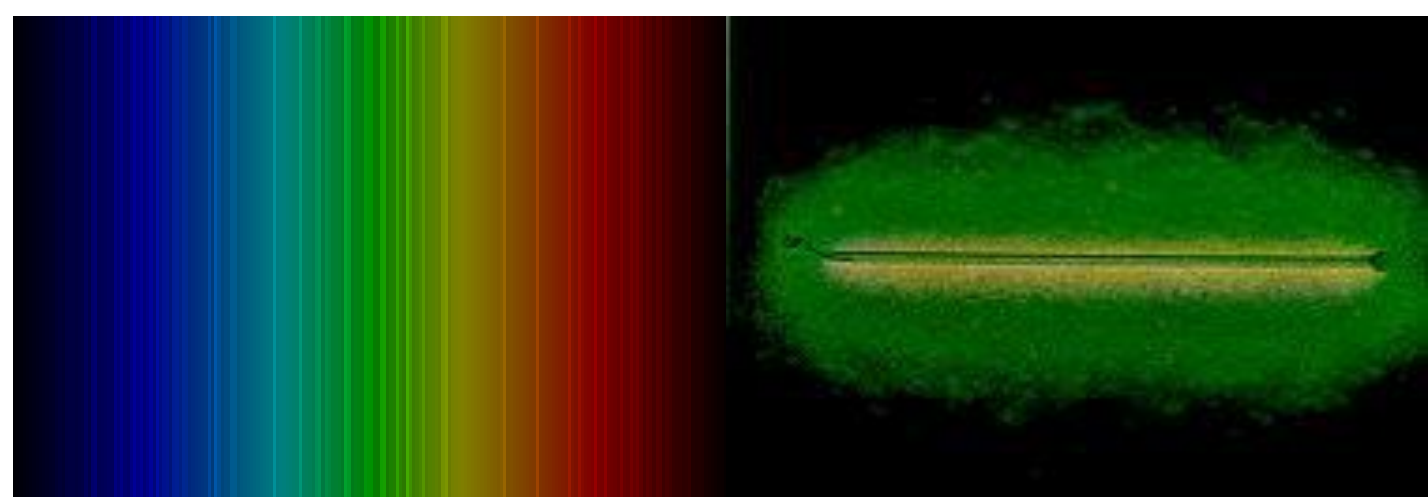

(a)

(b)

Fig2. Spectral lines of radon (a), and small gold tube filled with radon gas, causing radio luminescence of the phosphor layer below (b).

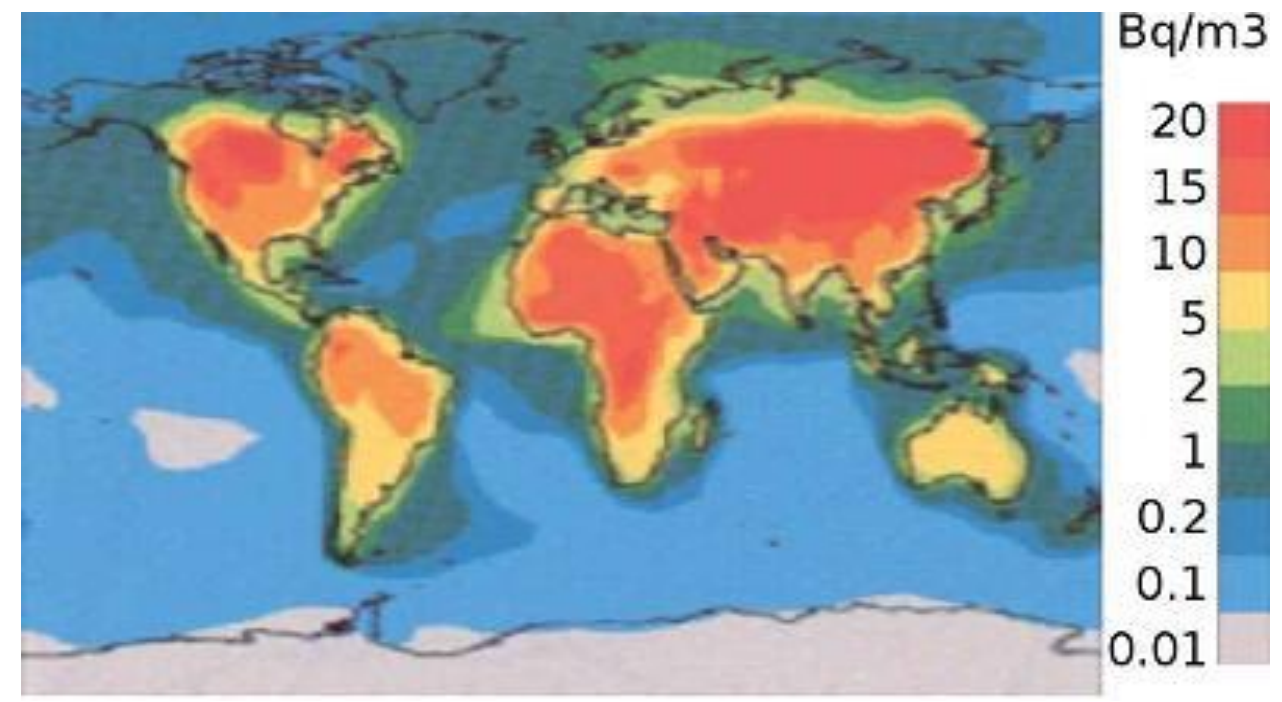

Fig3. Worldwide distribution of radon concentration.

The parent radionuclide of radon is radium, which has a very long half-life (1622 years). So, production of radon in the ground is essentially constant. In this concern, one should not to forget that radon is a chemical element with symbol Rn and atomic number 86. Also, radon can be considered as one of the densest substances that remain a gas under normal conditions. Finally, it is to be noted that radon gas seeps from the ground and can accumulate in areas that are exposed to Earth's crust and that have inadequate ventilation Fig. (4). In some parts of the country, it is required by law that homeowners place radon detectors in their basements to monitor the level of radon gas. For safety, whenever radon level exceeds the pre-determined radon safe level, the homeowner must take necessary actions reduce the level of radon gas, often by increasing the ventilation, the matter is due to its serious effect leading to death (Fig. 4c).

\subsection{Indoor Radon Exposure Limits}

According to the radiation exposure levels issued by the Canadian Nuclear Safety Commission (CNSC), two types of exposure limits-one for occupationally exposed persons and another for the general public were deduced [7]. In this concern, for annual occupational exposure - and general public -limits effective doses of $4.0 \mathrm{mSv}$ and $1.0 \mathrm{mSv}$ (milli-Sievert), respectively. (milli-Sievert). Also, these values are found in the Radiation Protection Regulations (SOR/2000-203) [8]. 


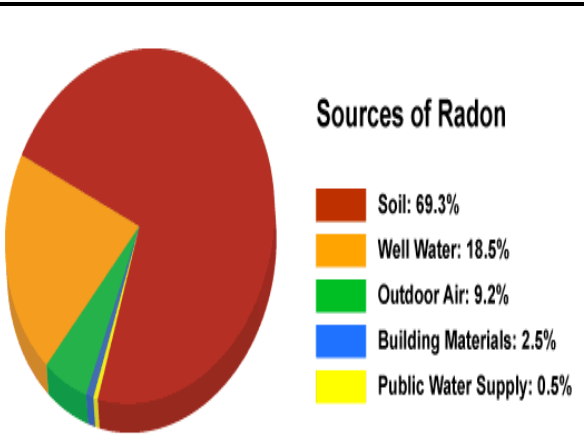

(a)

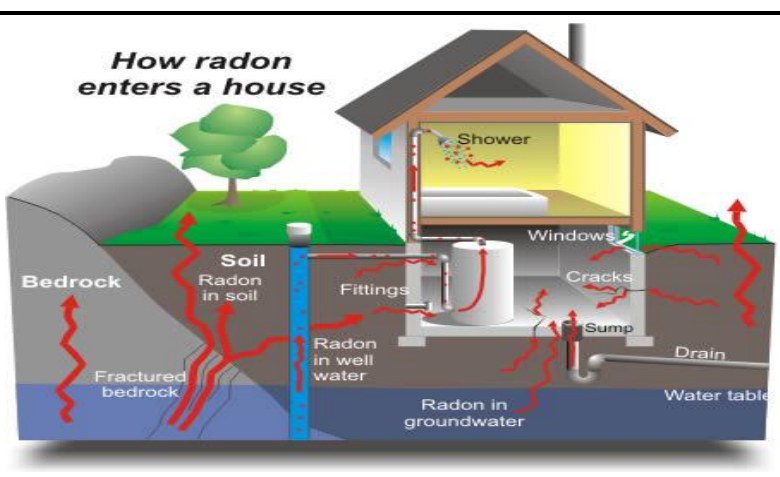

(b)

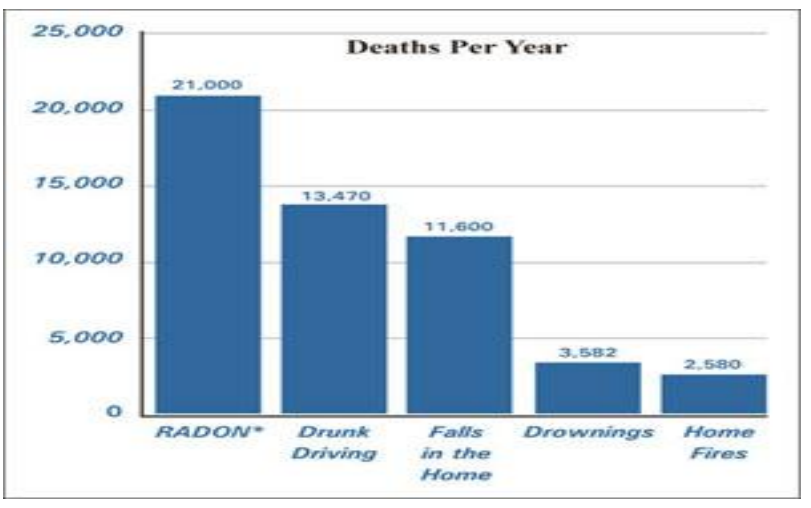

(c)

Fig4. Sources of radon (a), to indoor radon leakage (b), and deaths per year due to radon and others $(c)$.

\subsection{Radon Detection}

Indoor radon level is measured by air sampling and by alpha dosimetry using radon track etch dosimeters. A number of companies manufacture and sell measuring instruments. Since radon levels vary greatly from day to day, Health Canada recommends long-term sampling (3.0 to 12 months) to get a more accurate reading (e.g., at least 3.0 months and ideally during the winter to get a representative sample).

During a single day, the concentration of radon gas in indoor air varies widely and may easily double or triple (Fig. 5). Moreover, it is proved that radon levels fluctuate greatly from time to time; i.e., day to day, week to week, and season to season. The matter is mainly due to that radon normally drawn from the ground into homes by differences in concentration, air pressure, and temperature depending on the weather and ground conditions outdoors. On the other hand, the indoor radon level depends mainly on the barometric pressure, strong winds, rain-soaked ground, snow cover, the season, heating and $\mathrm{A} / \mathrm{C}$ systems, house construction, open windows, etc. [9].

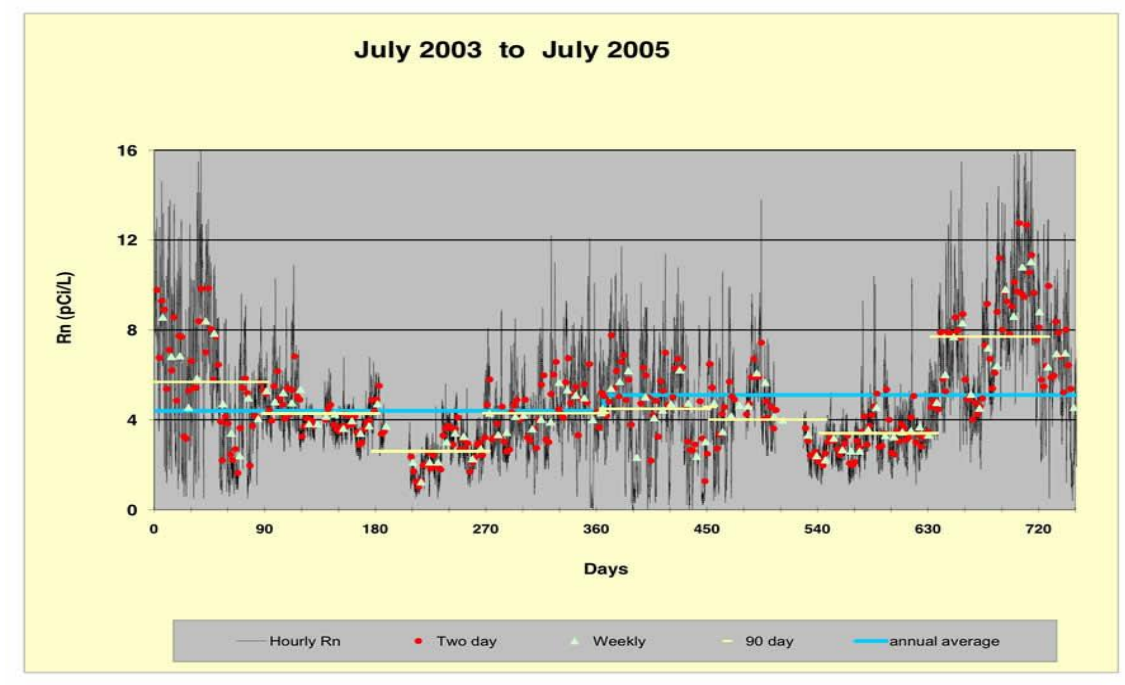

Fig5. Radon detection through the period July 2003- July 2005 [9]. 


\section{RTM 1688-2-RADON MONITOR}

Figure (6) shows the radon gas monitor of the type "RTM -1688-2". The unit is a wide spectrum radon monitoring system, provided with different environmental sensors and special software package for displaying the different monitored data (Fig. 7).

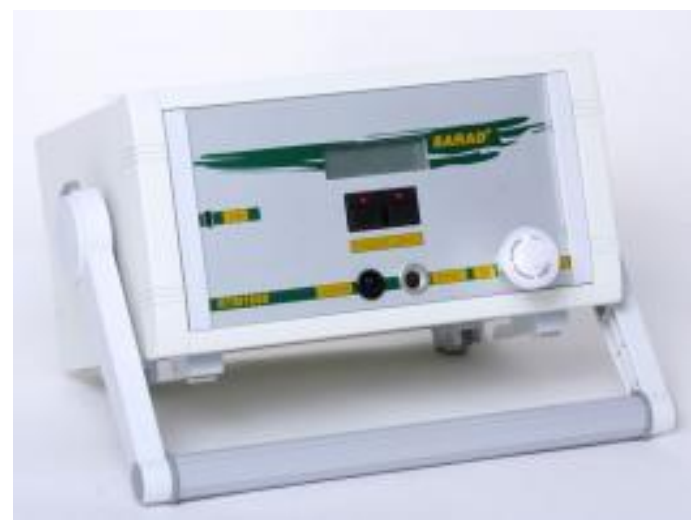

Fig6. RTM 1688-2-Radon Monitor.

\section{Specifications:}

Measurement Range: 0 ... $10 \mathrm{MBq} / \mathrm{m}^{3}$

Sensitivity 3/7 counts/min @ $1000 \mathrm{~Bq} / \mathrm{m}^{3}$ (Fast/Slow-Mode)

$200 \mathrm{~Bq} / \mathrm{m}^{3}$ with a $10 \%$ statistical error $(1 \sigma)$ at a $1.0 \mathrm{hr}$. sample interval

$10 \mathrm{~Bq} / \mathrm{m}^{3}$ with a $25 \%$ statistical error $(1 \sigma)$ at a $4.0 \mathrm{hr}$. sample interval

\section{Sensors included for:}

Relative humidity $(0 \ldots$... 100\%)

Temperature $\left(-20 \ldots 40^{\circ} \mathrm{C}\right)$

Barometric pressure $(800$... 1200 mbar)

Sample interval from $1.0 \mathrm{~min}$ to 4.0 hours, $1.0 \mathrm{~min}$ steps

Non-volatile memory for 2047 data records (circular), Alpha Spectrum for each included

Internal sampling pump ( $0.30 \mathrm{~L} / \mathrm{min}$ continuous and interval mode) Radon Vision Software included

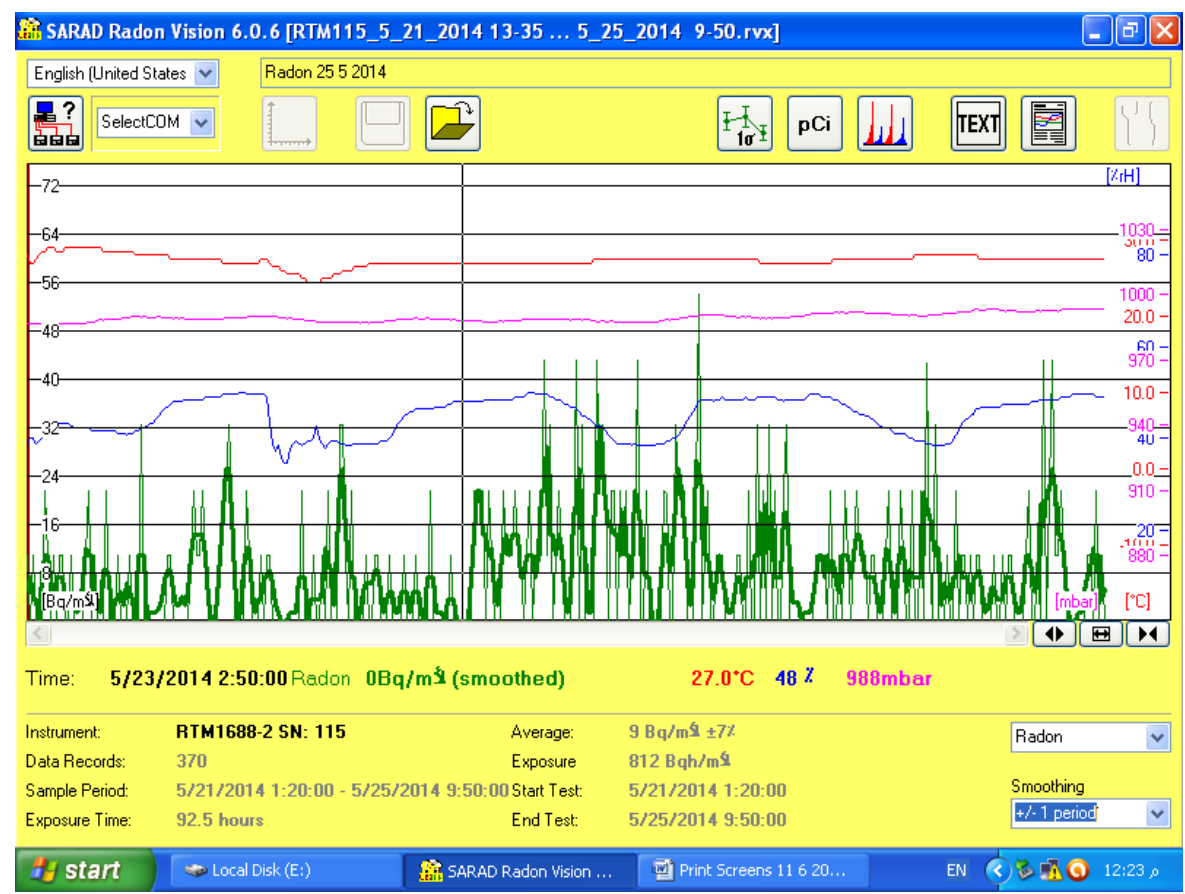

Fig7. Snapshot of RTM 1688-2-Radon monitor. 
Figure (8) shows, as an example, the radon concentration, temperature, relative humidity, and pressure levels, plotted at the Nuclear Materials Authority site, New Cairo, Cairo, Egypt, as a function of measuring time up to 120 hours.
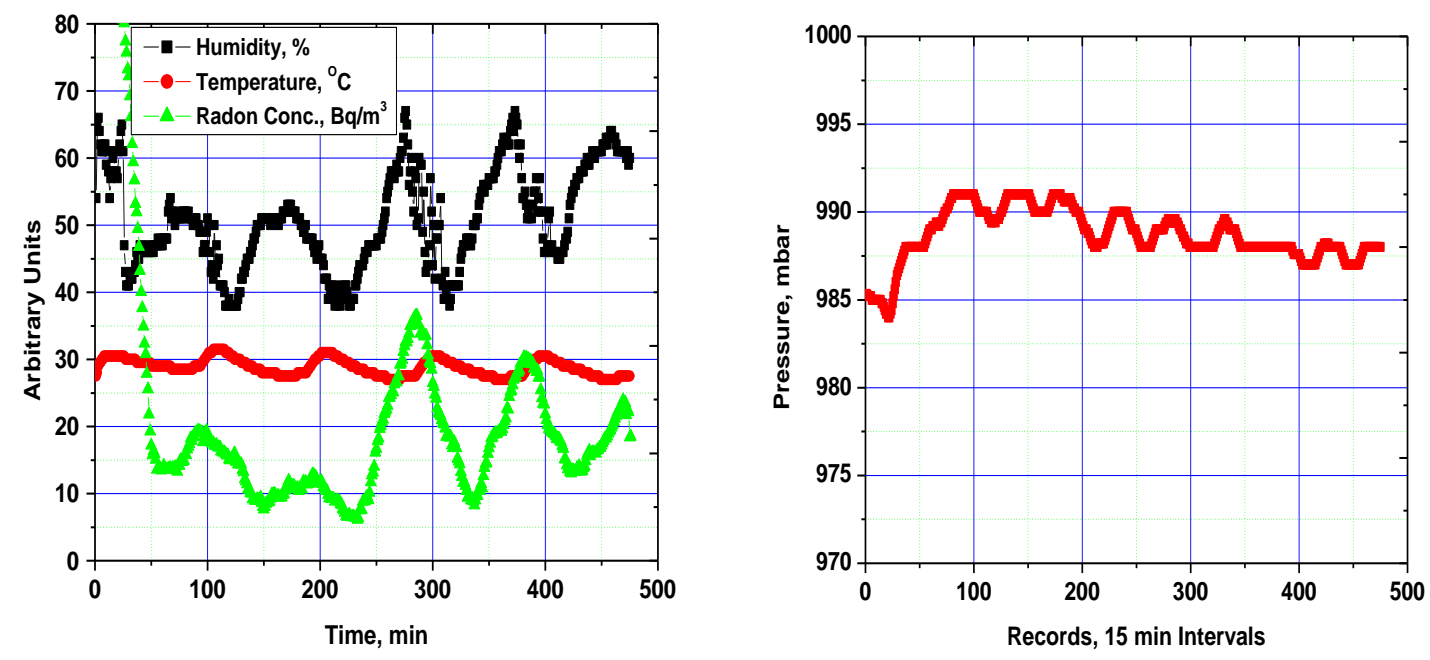

Fig8. Radon concentration, temperature, relative humidity and pressure, plotted as a function of measuring time up to 120 hours.

\section{IMPLEMENTATION OF RADON DETECTOR}

The radiation detector is based on a simple ionization chamber, which is in principle, a metal can with an elongated base of Darlington transistor. In this concern, Fig. (9) shows Darlington transistor with extended base lead (Fig. 9a), detector simple system (Fig. 9b), circuit diagram of a singly transistorlike Darlington pair using NPN or PNP transistors (Fig. 9c) and array devices (Fig. 9d). As well, the implementation steps of the proposed detector are shown in Fig. (10). When a radioactive particle passes through the air in the chamber under the influence of the fan, many of the molecules of air are ionized, having electrons knocked loose from the outer atomic shells. Biasing the system in the direction that the outer metal can to be positive relative to the internal wire, the mater which will causes the ions and electrons to move. The positive ions are attracted to the negatively charged wire, and the free electrons are attracted to the positively charged interior wall of the can. This movement of charge is a tiny current that can be amplified to detect the rate at which ions are being generated, and thereby the rate that radioactive particles are passing through the can. The transistor is an ordinary NPN like the MPSAW45A. The resistor can be any value above $1.0 \mathrm{k} \Omega$; it simply limits current in the event of a short circuit. Noting that the proposed chamber is capable of detecting extremely tiny currents, where:

- $10 \mathrm{mV}$ on the meter corresponds to $1.0 \mathrm{nA}$ flowing in the meter.

- Assuming the gain of the transistor is about 30,000, the base current is $10 \mathrm{nA} / 30,000=33 \mathrm{fA}$, a very tiny current. Noting that 1.0 fA corresponds to the flow of 6,240 electrons per second, so a change of $10 \mathrm{mV}$ represents a couple of hundred thousand electrons being liberated every second.

\subsection{Darlington Transistor}

In electronics, the Darlington transistor (often called a Darlington pair) is a compound structure consisting of two transistors put inside a single package, it acts like a single transistor that has high gain and high input impedance [10]. This configuration gives a much higher common/emitter current gain than each transistor taken separately and, in the case of integrated devices, can take less space than two individual transistors because they can use a shared collector [11]. Finally, Table (1) illustrates the electrical characteristics of the device.

Table1. Electrical characteristics of the MPSW45A Darlington transistor.

\begin{tabular}{|cc|}
\hline Parameter & Range \\
\hline Current - Collector, max & $1.0 \mathrm{~A}$ \\
\hline Collector-Emitter Voltage, max & $50 \mathrm{~V}$ \\
\hline DC-Current Gain, h $_{\mathrm{FE}}$ & 25000 @ $200 \mathrm{~mA}, 5.0 \mathrm{~V}$ \\
\hline Power, max & $1.0 \mathrm{~W}$ \\
\hline Frequency - & $100 \mathrm{MHz}$ \\
\hline
\end{tabular}




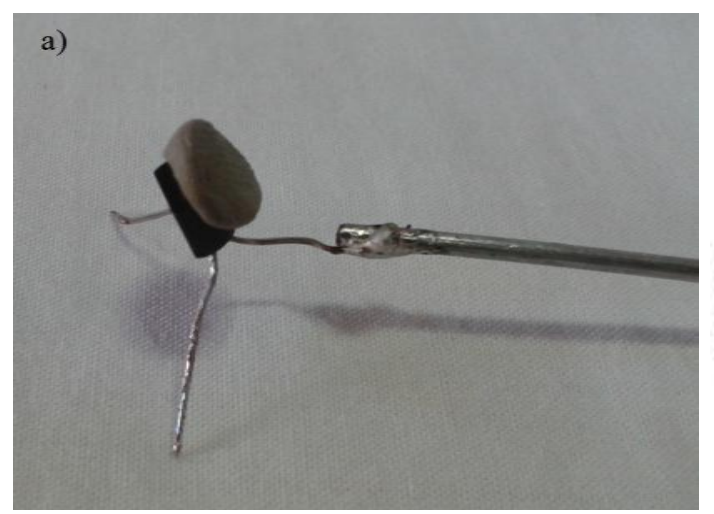

(a)

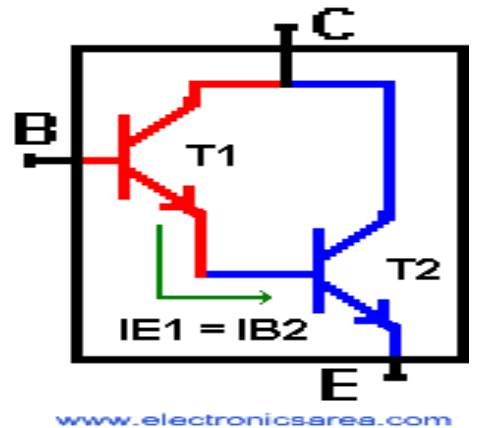

(c)

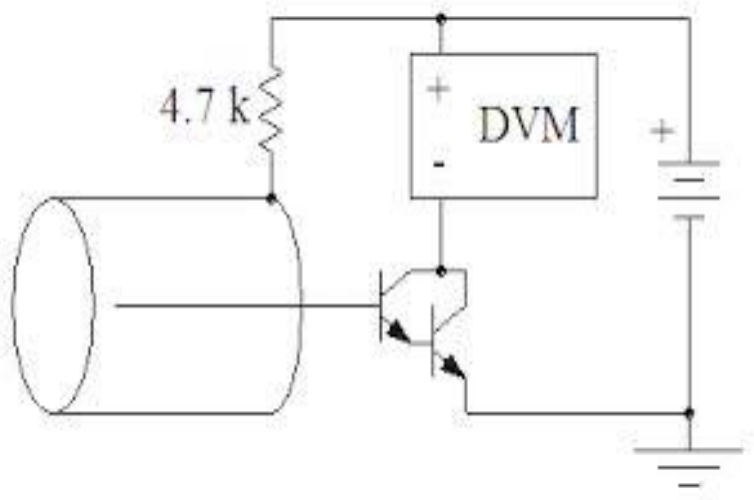

(b)

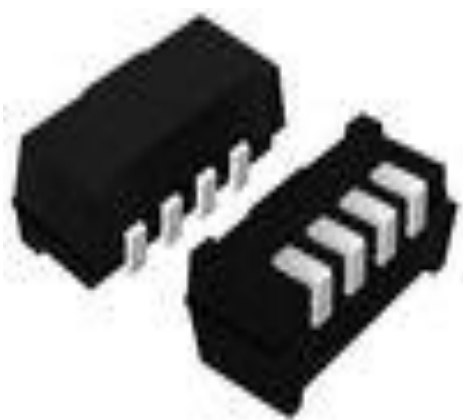

(d)

Fig9. Darlington transistor with extended base lead (a) detector simple system (b), circuit diagram of a singly transistor-like Darlington pair using NPN or PNP transistors $(c)$ and array devices $(d)$.
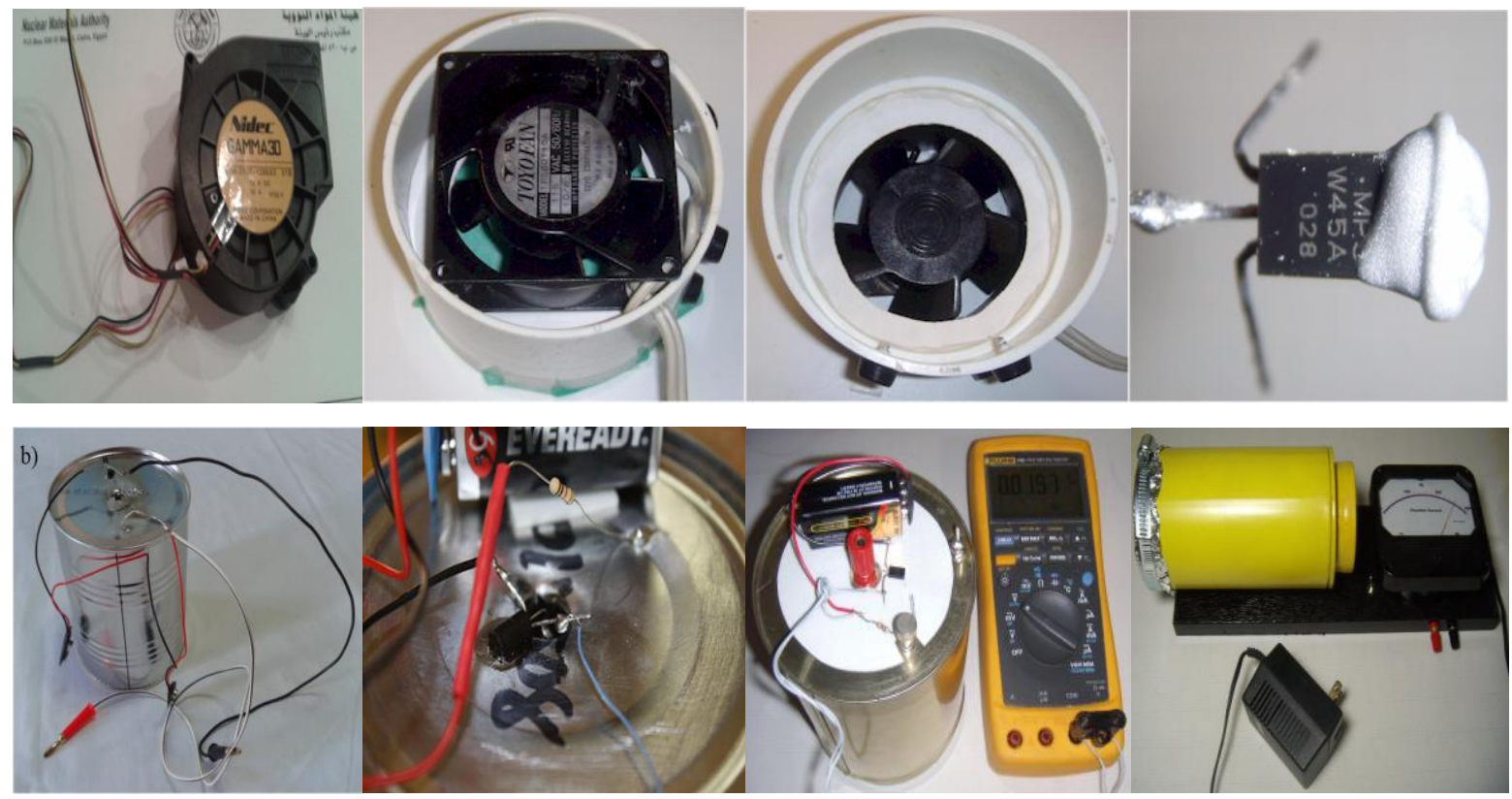

Fig10. Implementation steps of the radon detector.

When a ray passes through the chamber, several atoms are ionized and the positive voltage on the can attracts the electrons. The positively charged atoms wander to the more negative center wire and, upon contact, reclaim their missing electrons. This process results in a current flow in the base of the transistor which is amplified by a factor near 30,000. This higher current flows through the $10 \mathrm{M} \Omega$ resistance of the meter, producing the indicated voltage. As a point of reference, a reading of $10 \mathrm{mV}$ would correspond to roughly 200,000 electrons per second, so even weak radioactive sources produce large numbers of ions. 


\section{Measurement Locations}

Four different locations were chosen at the site of Nuclear Materials Authority of Egypt, New Cairo City, Cairo, Egypt for such test. They were (Fig. 11):

1. Well with depth of 2.0 meters, at a total volume of around $3.0 \mathrm{~m}^{3}$ (Fig. 11a),

2. A ground floor room with $4.0 \mathrm{~m} \times 3.5 \mathrm{~m} \mathrm{x} 6.0 \mathrm{~m}$ in dimensions, at a total volume of around $80 \mathrm{~m}^{3}$ (Fig. 11b),

3. A $3^{\text {rd }}$ floor room with $2.0 \mathrm{~m} \times 5.0 \mathrm{~m} \times 3.5 \mathrm{~m}$ in dimensions, at a total volume of around $35 \mathrm{~m}^{3}$ (Fig. $11 \mathrm{c})$, and

4. Basement room with $10 \mathrm{~m} \times 10 \mathrm{~m} \times 3.5 \mathrm{~m}$ in dimensions (with many of open windows), at a total volume of $350 \mathrm{~m}^{3}$ (Fig. 11d).

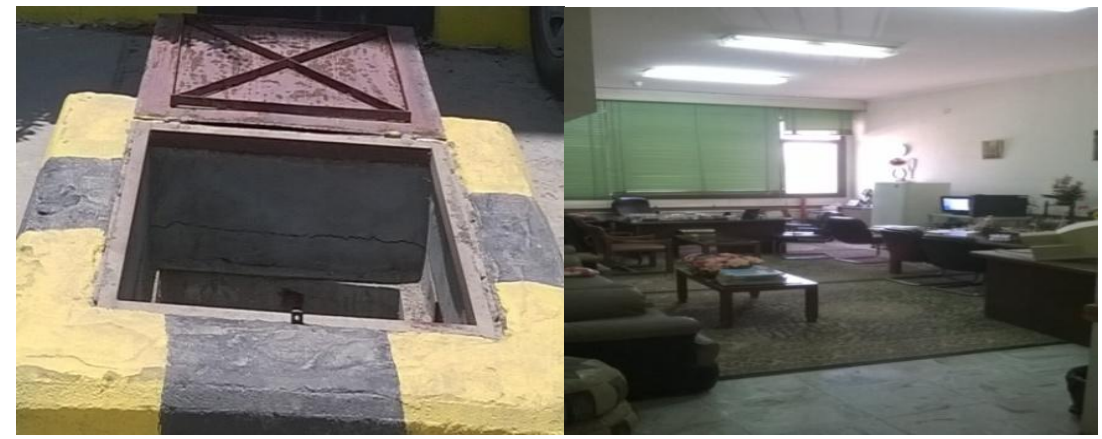

(a)

(b)

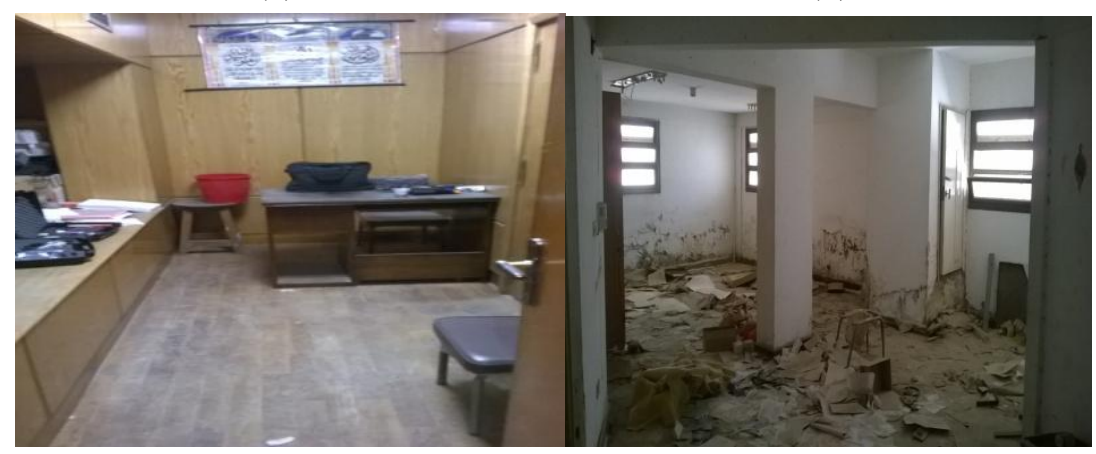

(c)

(d)

Fig11. Measurement locations at the Nuclear Materials Authority site.

\section{IndOOR Solar PoWering SySTEM}

Solar illuminations offer a large selection of indoor lighting - powering - systems. In this concern, an amorphous solar panels system was introduced for powering the radiation detector (Fig. 12). Generally, such panel is commonly used for indoor-applications, where it can harvest energy from fluorescent lamp $[12,13]$. Finally, the panel specifications were illustrated at Table (2).

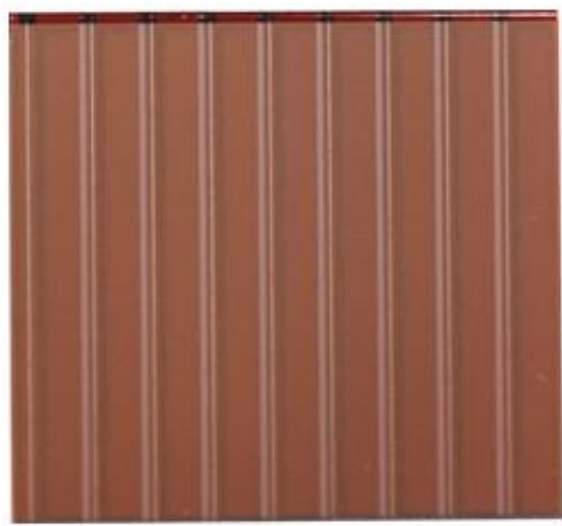

Fig12. Amorphous solar panel. 
Y.A. Abdel-Razek et al.

Table2. Specifications of the in-door Amorphous solar cell.

\begin{tabular}{|c|c|c|c|c|c|}
\hline Item No. & Voc & Isc & Vout & Dimensions & Illumination Level \\
\hline E-28 & $4.0 \mathrm{~V}$ & $9.1 \mu \mathrm{A}$ & $\mathbf{3 . 0} \mathrm{V}$ & $27 \times 27 \times 1.1 \mathrm{~mm}$ & 200 lux. \\
\hline
\end{tabular}

Figure (13) shows the output characteristic curves of a single amorphous silicon solar panel, illuminated using fluorescent lamp, incandescent lamp, and infra-red lamp, respectively. From which, it is clearly shown that the proposed solar panels operates under indoor illumination levels down to the range from 700 lux down to 50 lux, where the chosen illumination levels were investigated according to the normal indoor lighting levels illustrated at Table (3). Noting that full solar illumination level reaches the value of around 100000 lux [14-16].

Table3. Light level in different work spaces.

\begin{tabular}{|c|c|}
\hline Activity & Illumination, lux \\
\hline Public areas with dark surroundings & $\mathbf{2 0}-\mathbf{5 0}$ \\
\hline Simple orientation for short visits & $\mathbf{5 0}-\mathbf{1 0 0}$ \\
\hline Working areas (visual tasks are only occasionally performed) & $100-150$ \\
\hline Warehouses, homes, theaters, and archives & 150 \\
\hline Easy office work, and classes & $\mathbf{2 5 0}$ \\
\hline Normal office work, PC-work, study library, groceries, show rooms, and & $\mathbf{5 0 0}$ \\
\hline laboratories & $\mathbf{7 5 0}$ \\
\hline
\end{tabular}

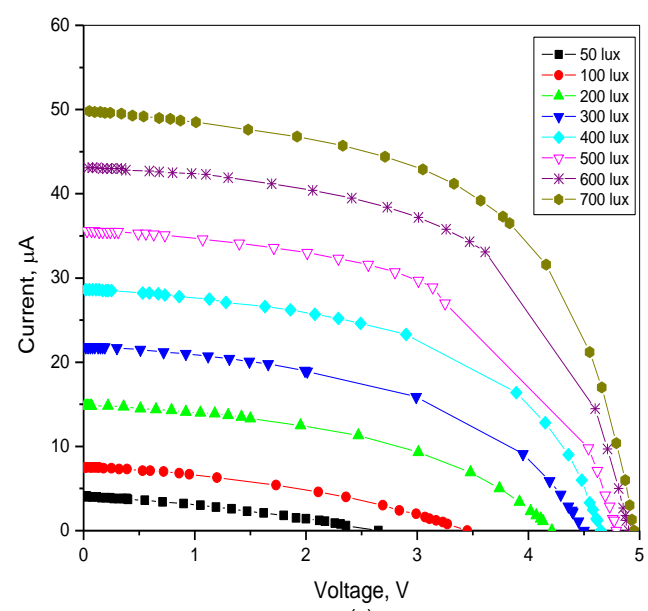

(a)

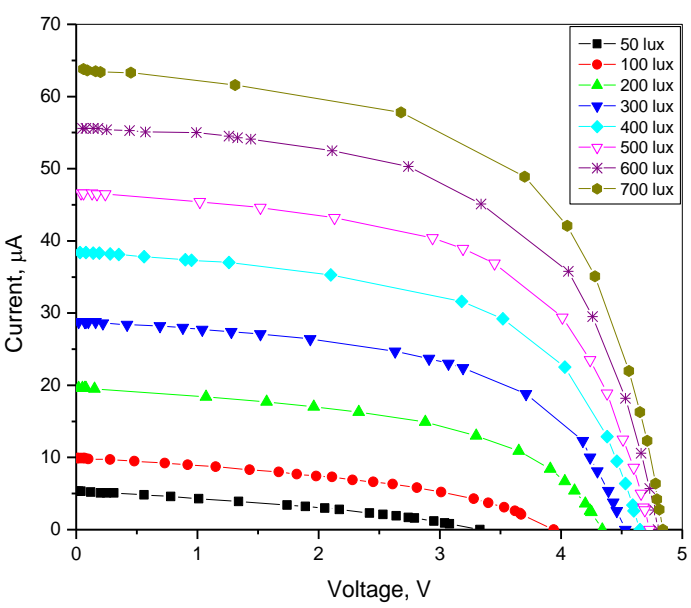

(b)

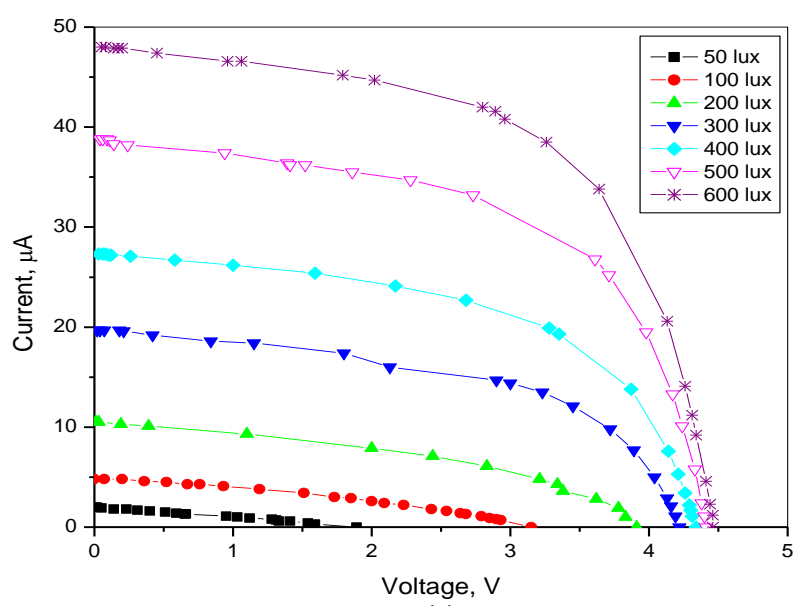

(c)

Fig13. Output electrical characteristic curves of indoor solar panel, illuminated using (a) fluorescent lamp, (b) incandescent lamp and (c) infra-red lamp, respectively. 


\section{RADON MONITORING RESULTS}

Figure (14) shows the spectra of both the radon concentrations, plotted at the four locations for a total time of around 95-130 hours using the RTM 1688-2-radon monitor. Also, Fig. (15) shows the output voltages of the proposed electronic detector traced for a total time up to around 45 hours, plotted at the same four locations. From which, the dependence of the average value of the detector output voltage on radon concentrations, measured at four locations, was shown in Fig. (16). It is clearly shown that a close excellent agreement was obtained where a correlation value of 0.98751 was reported.
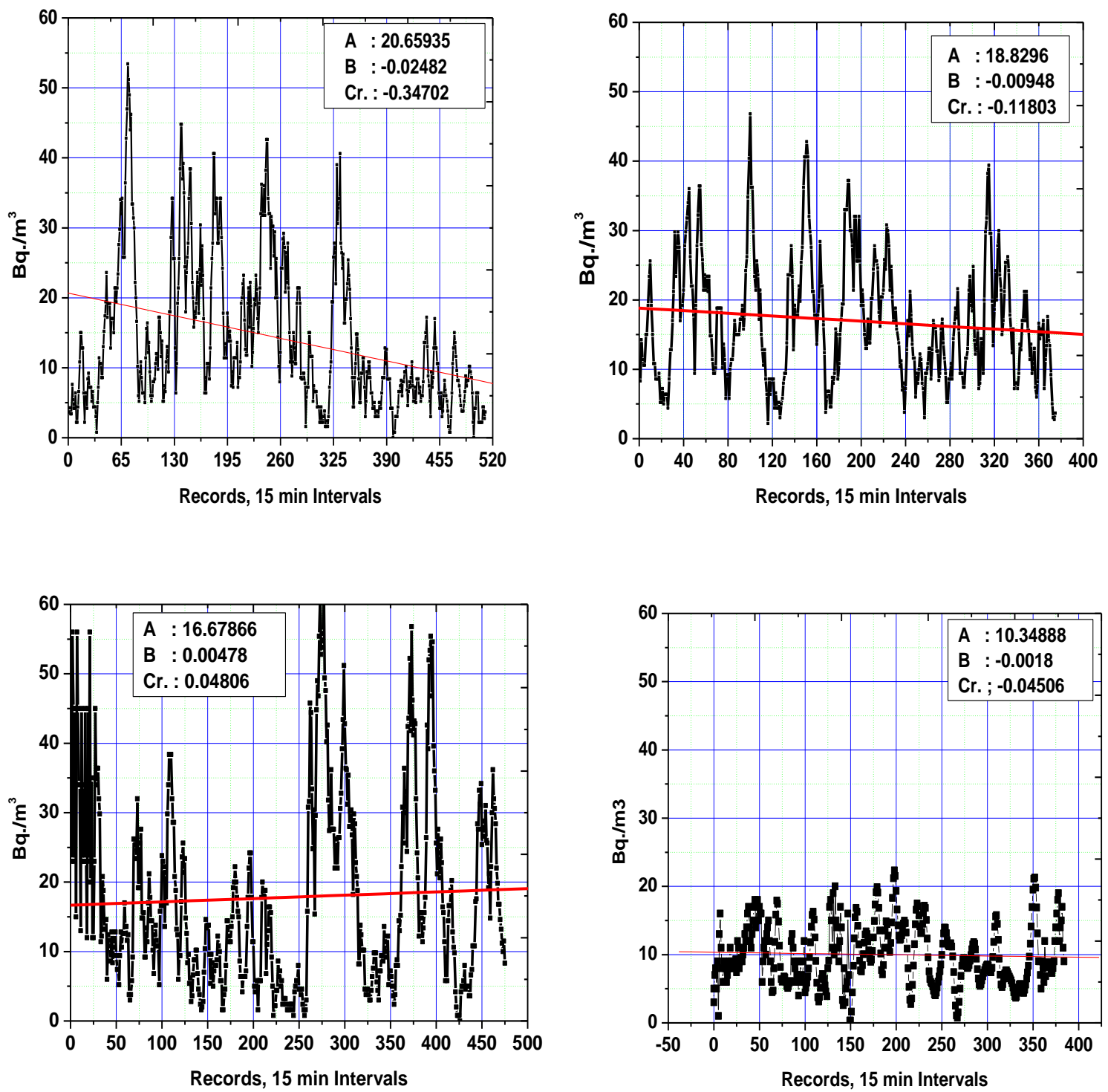

Fig14. Spectra of the radon concentrations, plotted at the four locations, respectively, for a total of around 95 130 hours. 

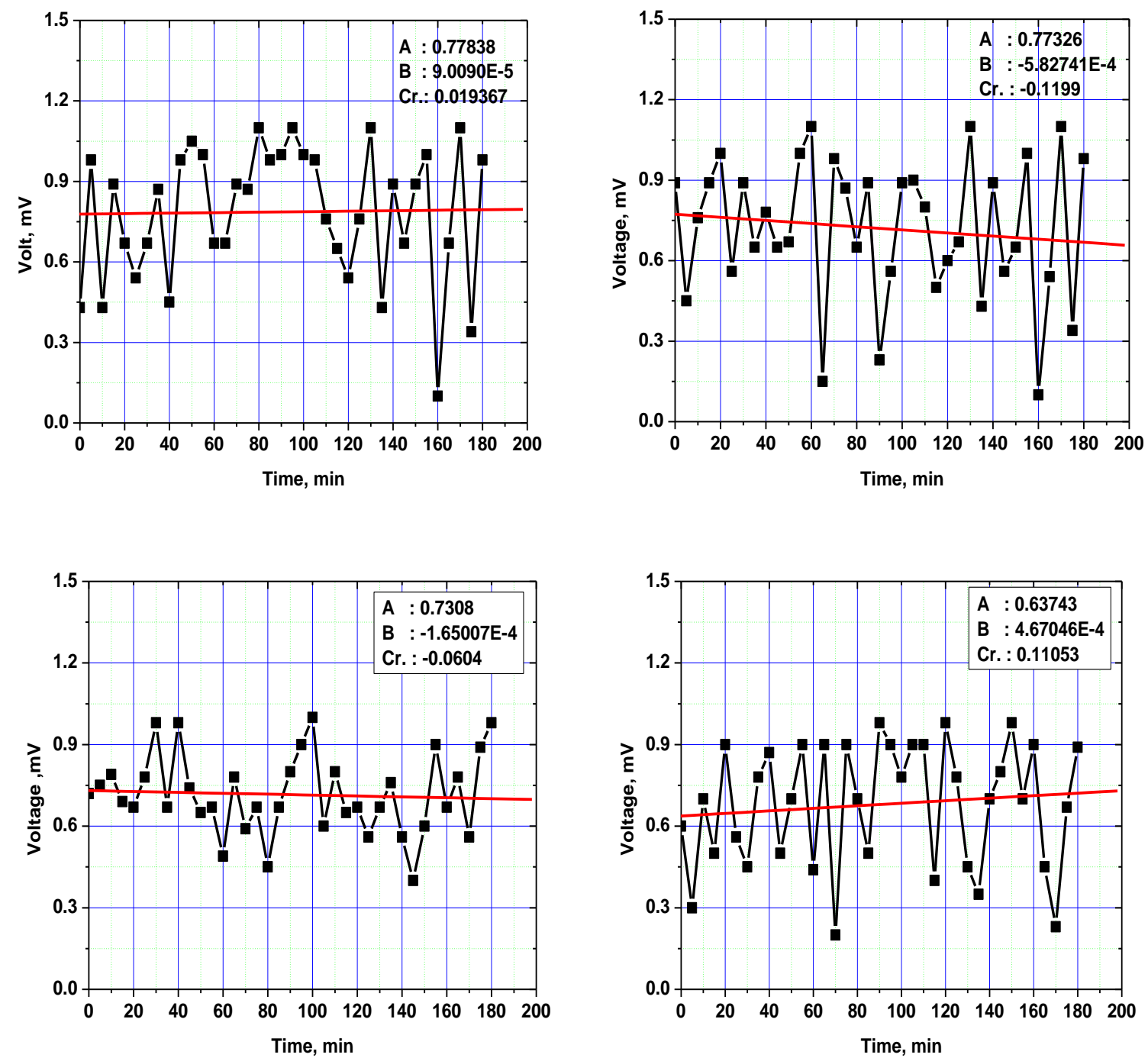

Fig15. Output voltages of the proposed electronic detector for a total time up to around 45 hours, plotted at the different four locations.

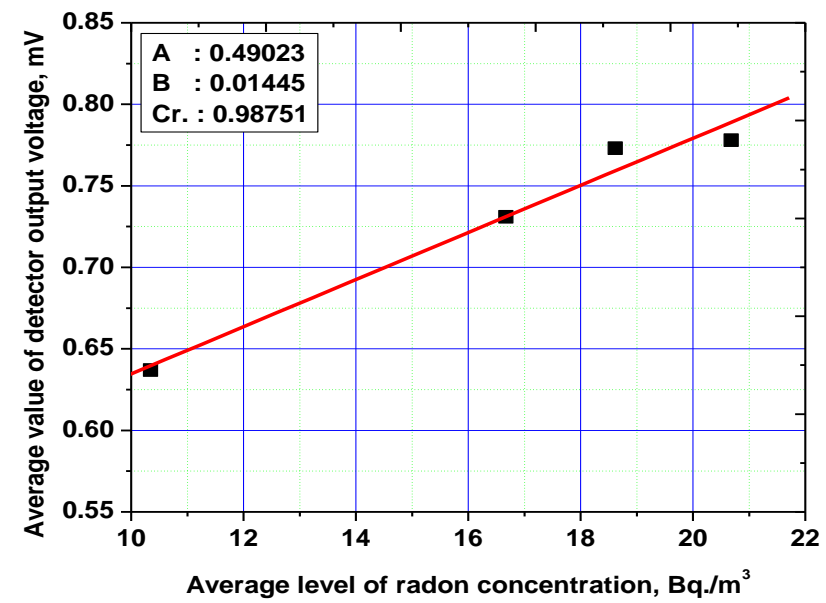

Fig16. Dependence of the average value of the detector output voltage on radon concentrations, measured at four locations.

\section{Conclusions}

A prototype ion-chamber radon monitoring system based on a single transistor was investigated, implemented and applied for measurements of radon gas concentrations on different locations. The 
obtained data from the proposed system was correlated to that obtained using the well-known radon monitoring system (RTM-1688-2 radon monitor), where it was found that an excellent agreement was obtained between both systems.

\section{REFERENCES}

[1] Askari Mohammad Bagher, Mirzaei Vahid and Mirhabibi Mohsen, " Introduction to Radioactive Materials", International Journal of Renewable and Sustainable Energy, 3(3), p. 59-67, 2014.

[2] Riccardo Borgoni, Valeria Tritto, Carlo Bigliotto and Daniela de Bartolo, "A Geostatistical Approach to Assess the Spatial Association between Indoor Radon Concentration, Geological Features and Building Characteristics: The Case of Lombardy, Northern Italy", Int. J. Environ. Res. Public Health, 8(5), p. 1420-1440, 2011.

[3] R.W. Field, et al., "Residential Radon Gas Exposure and Lung Cancer", American Journal of Epidemiology, 51(11), p. 1091-1102, 2000.

[4] Ojo T. J and Ajayi I. R , " A Review on Environmental Radon and Its Potential Health Risk on Humans", IOSR Journal Of Environmental Science, Toxicology And Food Technology (IOSRJESTFT), 8(1) Ver. IV, p. 01-08, Feb. 2014.

[5] R.W. Field, D.J. Steck, B.J. Smith, "Residential Radon Gas Exposure and Lung Cancer: the Iowa Radon Lung Cancer Study", American Journal of Epidemiology, 151(11), p. 1091-1102, 2000.

[6] M. Jashank, J. S. Gupta, and J. Nair, "Development of Radon Gas Sensor to Monitor the Precursors of Earthquake", IOSR Journal of Engineering (IOSRJEN), 4(1), p. 10 -15, Jan. 2014.

[7] M. Möhner, J. Gellissen, J.W. Marsh, and D. Gregoratto, "Occupational and diagnostic exposure to ionizing radiation and leukemia risk among German uranium miners. Health Physics, 99(3), p. 314-321, 2010.

[8] International Atomic Energy Agency, "IAEA Safety Standards: Radiation Protection and Safety of Radiation Sources: International Basic Safety Standards for protecting people and the environment", GSR Part 3, Vienna, 2003.

[9] http://www.free-radon-test-kits.com/short-long-tests.htm

[10] Sanyokita Singh, Braj Bihari Soni and "Review on Darlington Transistor for Recent Modern Application", International Journal of Computer Applications, 112(10), p. 1-3, February 2015.

[11] K. Avinash Babu, "Cost Less Transistorized Inverter", International Journal of Engineering Research \& Technology (IJERT), 2(4), P. 1078- 1087, April - 2013.

[12] R. W. Collins, et al., "Evolution of Microstructure and Phase in Amorphous, Protocrystalline, and Microcrystalline Silicon Studied by Real Time Spectroscopic Ellipsometry", Solar Energy Materials and Solar Cells, 78(1-4), p. 143-180, July 2003.

[13] J. M. Pearce, N. Podraza, R. W. Collins, M. M. Al-Jassim, K. M. Jones, J. Deng and C. R. Wronski, "Optimization of Open Circuit Voltage in Amorphous Silicon Solar Cells with MixedPhase (Amorphous+Nanocrystalline) P-Type Contacts of Low Nanocrystalline Content", Journal of Applied Physics, 101, p. 114301-1- 114301-7, 2007.

[14] F.A.S. Soliman, "Measurements of Solar Radiation in Egypt During the Period 1982-1987", 1st Intr. Conf. on Re-Newable Energy Sources, Cairo, Egypt, 13 - 16 June 1988, Vol. 1, p. 379-387.

[15] F.A.S.Soliman, M.H.EL-Fouly, M.B.Seleh, and M.EL-Ashry, " Fabrication and Characteriztion of Silicon Photovoltaic Cells for Solar Energy Conversion”, 1st World Renewable Energy Congress, Reading, U.K, 23-28 Sept. Vol. 1, p. 135-141, 1990, Pergamon Press.

[16] F.A.S.Soliman, M.El-Fouly and M.El-Ashry, "Photovoltaic Devices: Simulation, Properties and the Effects of Physical Parameters", Intr. Jr. of Perspectives in Energy, Moscow Intr. Center, Russia, Printed at Pion Publ., Ltd., U.K., 3, p. 35-46, Oct. 1995. 


\section{AUTHOR'S BIOGRAPHY}

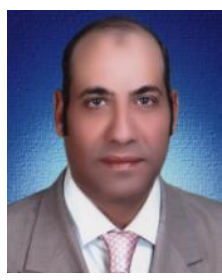

Yassin A. Abdel-Razek, Assistant professor in physics at the Nuclear Materials Authority,Cairo, Egypt. A qualified expert in radiation protection. A specialist in the field of radioactive materials of terrestrial origin.
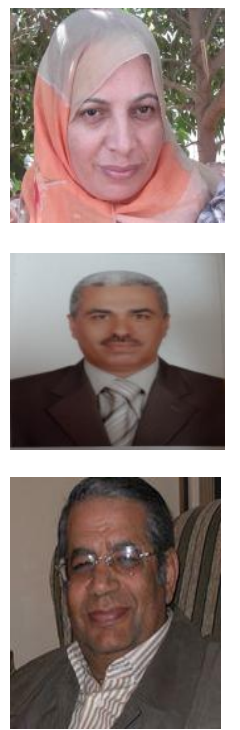

Wafaa Abd El-Basit, Egyptian physicist and lecturer of Electronics in physicselectronics, from Physics Department, Faculty of Women for Ats, Science and Education, Ain-Shams University, Cairo, Egypt. Major field of interest: physics; special field of interest: electronics, computer simulation and programming, and energy.

Ashraf Mosleh Abd El-Maksood, Lecturer of Electronics Engineering, Electronics Eng. Dept., Nuclear Materials Authority of Egypt. Major field of interest: Energy, Electronics, Radaition detection and computer programming and simulation.

Fouad A. S. Soliman, Professor of Electronics and computers Eng., Nuclear Materials Authority of Egypt. Member of American Assoc. for Adv. of Sci's., N.Y., U.S.A and New York Academy of Sciences, New York, U.S.A.Editorial Board Member of: Progress in Photovoltaics "Research and Applications', John Wiley and Sons, UK, Periodicals of the Assoc. for Adv. of Modeling and Simulation Tech's., AMSE, Lune, France, Intr. Journal of Computer Sci. and Eng. Applications (IJCSEA). Chosen For: Who's Who in the World, A.N. Marquis, N.J., USA, and Outstanding People of the $20^{\text {th }}$ Century, Intr. Biographical Center of Cambridge, England. Published three Books at Lambert Academic Publi-shing, LAP, Saarbrücken, Germany, ISBN 978-3-659-83496-7, ISBN 978-3-65988129-9, and "ISBN 978-3-659-89387-2. 